\title{
Combinatorial Screening of Cuprate Superconductors by Drop-On- Demand Inkjet Printing
}

\author{
Albert Queraltó,* Juri Banchewski, Adrià Pacheco, Kapil Gupta, Lavinia Saltarelli, Diana Garcia, \\ Núria Alcalde, Cristian Mocuta, Susagna Ricart, Flavio Pino, Xavier Obradors, and Teresa Puig*
}

Cite This: ACS Appl. Mater. Interfaces 2021, 13, 9101-9112

Read Online

\section{ACCESS |}

Џlll Metrics \& More

Article Recommendations

Supporting Information

ABSTRACT: Combinatorial and high-throughput experimentation (HTE) is achieving more relevance in material design, representing a turning point in the process of accelerated discovery, development, and optimization of materials based on data-driven approaches. The versatility of drop-on-demand inkjet printing (IJP) allows performing combinatorial studies through fabrication of compositionally graded materials with high spatial precision, here by mixing superconducting REBCO precursor solutions with different rare earth (RE) elements. The homogeneity of combinatorial $\mathrm{Y}_{1-x} \mathrm{Gd}_{x} \mathrm{Ba}_{2} \mathrm{Cu}_{3} \mathrm{O}_{7}$ samples was designed with computational methods and confirmed by energy-dispersive $\mathrm{X}$ ray spectroscopy (EDX) and high-resolution X-ray diffraction

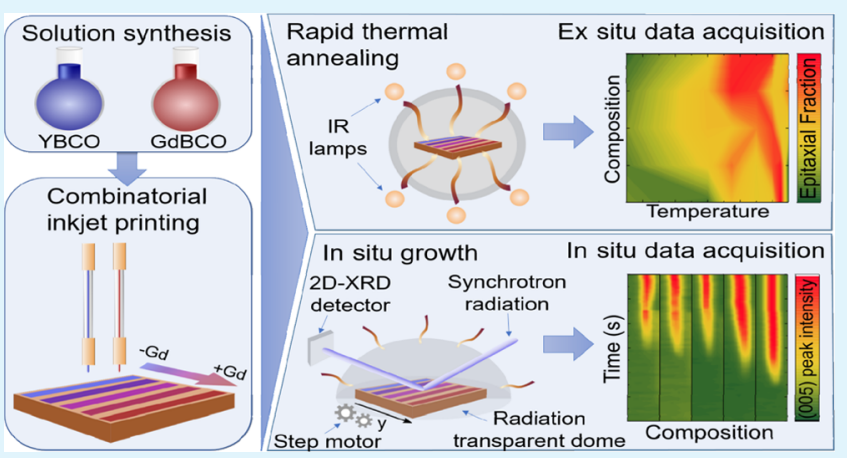
(XRD). We reveal the advantages of this strategy in the optimization of the epitaxial growth of high-temperature REBCO superconducting films using the novel transient liquid-assisted growth method (TLAG). Advanced characterization methods, such as in situ synchrotron growth experiments, are tailored to suit the combinatorial approach and demonstrated to be essential for HTE schemes. The experimental strategy presented is key for the attainment of large datasets for the implementation of machine learning backed material design frameworks.

KEYWORDS: combinatorial chemistry, high-throughput experimentation, superconducting materials, inkjet printing, transient liquid-assisted growth, cuprate superconductors, chemical solution deposition

\section{INTRODUCTION}

High temperature superconducting (HTS) materials are regarded as key players toward an effective renewable energy transition. The unique properties of superconductors (e.g., large current transport without losses) and the development of novel strategies for high power managing and transportation based on HTS are foreseen to pave the way toward cuttingedge and energy-efficient technologies in sectors such as clean electrical energy (cables, transformers, motors, generators, fusion reactors), biomedicine and chemistry (magnetic resonance imaging), scientific instrumentation (ultrahigh magnetic fields), or transportation (hybrid/electric airplanes and ships). ${ }^{1-4}$

Superconducting $\mathrm{REBa}_{2} \mathrm{Cu}_{3} \mathrm{O}_{7}$ (REBCO, $\mathrm{RE}=$ rare earth) films and coated conductors (CC) possess an inherent advantage due to the high performances in a significantly broad spectrum of the magnetic field-temperature $(B-T)$ diagram, hence showing promising properties for wide market implementation. ${ }^{5}$ Due to historical reasons, YBCO has been the most investigated REBCO superconductor. ${ }^{6}$ Nevertheless, a wide range of $\mathrm{RE}$ ions that can replace $\mathrm{Y}$ are driving the current research interest. The main motivation is the higher critical temperature $\left(T_{\mathrm{c}}\right)$ for RE such as $\mathrm{Gd}$ or $\mathrm{Sm}$ as compared to $\mathrm{Y}$, which contributes to broadening the magnetic field region for applications (i.e., high irreversibility line), consequently, enhancing current densities $\left(J_{c}\right)$ and pinning forces $\left(F_{\mathrm{p}}\right)$ at relevant temperatures. For instance, values of $J_{\mathrm{c}}>$ $7 \mathrm{MA} \mathrm{cm}{ }^{-2}(77 \mathrm{~K}, B=$ self-field, on STO $)$ and maximum $F_{\mathrm{p}} \sim$ $16 \mathrm{GN} \mathrm{m}^{-3}(77 \mathrm{~K}, B=2 \mathrm{~T}$, on STO) have been reported for $\mathrm{GdBCO}$ and $\mathrm{BaHfO}_{3}$ nanoinclusions ${ }^{7}$ or $J_{\mathrm{c}}>6 \mathrm{MA} \mathrm{cm}^{-2}(77$ $\mathrm{K}, B=$ self-field, on LAO) and $F_{\mathrm{p}} \sim 28 \mathrm{GN} \mathrm{m}^{-3}(77 \mathrm{~K}, B=1.5$ $\mathrm{T}$, on $\mathrm{LAO}$ ) for $\mathrm{BaHfO}_{3}$-doped $\mathrm{SmBCO}^{8}{ }^{8}$ Despite the good properties exhibited in some cases, the exploration of other RE is still scarce, sometimes limited by stability or synthesis complexity of some REBCO phases. The focus has been shifted in recent years to RE mixing such as $\mathrm{Y} / \mathrm{Gd},{ }^{6,9,10} \mathrm{Gd} /$ $\mathrm{Yb},{ }^{11,12} \mathrm{Y} / \mathrm{Sm},{ }^{13,14}$ and $\mathrm{Dy} / \mathrm{Gd},{ }^{15}$ aiming to overcome such predicaments, as well as to shed light on the right combination that enables best superconducting properties.

Received: October 7, 2020

Accepted: December 23, 2020

Published: February 12, 2021 
The initial push of the superconductor industry has been made with several film deposition techniques to achieve epitaxial growth; mandatory to transport large electric currents through the material. Among them, chemical solution deposition (CSD) is demonstrated to be a very promising low-cost approach for REBCO film growth with high manufacturing perspective into $\mathrm{CC}$ tapes, through the use of reel-to-reel compatible deposition methodologies, such as inkjet printing or slot-die coating. ${ }^{16,17}$ Despite the industrialization process has seen significant advancements, reaching very attractive total critical currents of $\sim 700 \mathrm{~A} / \mathrm{cm}$ width at 77 $\mathrm{K}$, the cost/performance ratio of CC technology is still limited due to insufficient growth rates $(1-10 \mathrm{~nm} / \mathrm{s}) .{ }^{18}$ Although liquid phase-assisted fabrication methods have been reported to allow faster growth rates due to the large diffusivity of atoms in the liquid, ${ }^{19,20}$ it has not been until very recently that a novel CSD strategy, known as transient liquid-assisted growth or TLAG-CSD, has been reported to greatly boost the growth rate of epitaxial YBCO films and nanocomposites $(\sim 100 \mathrm{~nm} /$ s) through the use of nonequilibrium growth conditions. A rapidly induced transient $\mathrm{Ba}-\mathrm{Cu}-\mathrm{O}$ liquid promotes the fast diffusion of RE ions to the growth front and allows a much faster epitaxial growth. ${ }^{21}$ Due to the novelty of the process, many aspects are still unexplored, such as the processing parameter window to achieve a high control of epitaxial nucleation and crystallization, the influence of different rare earth elements on the $P_{\mathrm{O}_{2}}-T$ conditions or the liquid composition. The optimization of such a large number of parameters requires fast screening methods for highthroughput sample fabrication, combined with smart solutions in characterization and data analysis.

Two decades ago, Evans et al. described the philosophy behind the combinatorial chemistry approach to push forward the development of inorganic materials. ${ }^{22}$ This strategy relies on the fabrication of large arrays of microsamples that are treated together or individually and characterized using adequate techniques that allow a fast evaluation of the processing parameters. The produced data is stored on large relational databases that can be later analyzed using computational methods to find the optimal compositions and processing conditions. Eventually, this allows researchers to focus on the interpretation of results and is prospected to speed up the discovery of materials. Nowadays, this strategy is starting to flourish, thanks to the development of data-driven methods based on big data analysis tools, machine learning algorithms, and other computational methods. ${ }^{23-28}$ Highthroughput experimentation (HTE) strategies, based on the combinatorial chemistry approach, are currently being researched in many diverse fields such as solar cells, ${ }^{29-31}$ lithium-ion batteries, ${ }^{32-34}$ electronics, ${ }^{35-37}$ water splitting, ${ }^{38,39}$ and superconductivity. ${ }^{40,41}$

From several deposition techniques available for the assembly of combinatorial test pieces, ${ }^{40-44}$ drop-on-demand inkjet printing (DoD IJP) appears as an ideal technique since it allows the fabrication of complex-shaped samples suitable for high-throughput measurement procedures and also achieves locally uniform and graded compositions. In this work, we propose a strategy based on a combinatorial chemistry approach by working with a DoD IJP for the mixing of different REBCO inks. This approach will contribute to the full disclosure of optimal ultrafast TLAG-CSD processing conditions through the exploration of the $\mathrm{PO}_{2}-T$ nonequilibrium kinetic phase diagram of REBCO films, contributing to the understanding of the kinetic influence of the growth process for the different compositions and, eventually, leading to the optimal growth rates and functional properties of superconducting coated conductors.

\section{EXPERIMENTAL SECTION}

Ink Formulation and Characterization. Metalorganic precursor $\mathrm{REBCO}(\mathrm{RE}=\mathrm{Y}$ and $\mathrm{Gd})$ inks with a stoichiometry $\mathrm{REBa}_{2} \mathrm{Cu}_{4.66} \mathrm{O}_{x}$ and a final concentration of $0.75 \mathrm{M}$ were used to prepare combinatorial samples. Commercial $\mathrm{Cu}(\mathrm{ac})_{2}$ salts (Merck KGaA) and in-house synthesized Y/Gd and Ba propionate were employed. The selected ink stoichiometry correlates with the $\mathrm{Ba}-\mathrm{Cu}-\mathrm{O}$ eutectic liquid composition $\left(3 \mathrm{BaCuO}_{2}-4 \mathrm{CuO}\right)$, which enables the crystallization of REBCO films at lower temperatures. ${ }^{21}$ First, a solvent mixture of propionic acid (PPA) and butanol $(\mathrm{BuOH})$ in a 50:50 ratio was added into a flask. ${ }^{16}$ Different $\%_{\mathrm{v} / \mathrm{v}}$ ethanolamine (EA) were added to the solvent mixture. EA acts as a complexing agent for $\mathrm{Cu}(\mathrm{ac})_{2}$, improves ink solubility and homogeneity, and provides enough viscosity to avoid excessive liquid movement during inkjet deposition. Subsequently, $\mathrm{Ba}(\text { prop })_{2}$ and $\mathrm{Cu}(\mathrm{ac})_{2}$ salts were slowly added under continuous stirring and kept for approximately $30 \mathrm{~min}^{34}$ Finally, $\mathrm{Y}(\text { prop })_{3}$ or $\mathrm{Gd}(\text { prop) })_{3}$ were added to the mixture and left stirring at $30{ }^{\circ} \mathrm{C}$ until a homogeneous and transparent solution was obtained, i.e., typically 30-60 $\mathrm{min}$. The precursor solutions were filtered through a polytetrafluoroethylene (PTFE) membrane filter (pore size $\sim 0.2 \mu \mathrm{m}$ ).

Surface tension and viscosity measurements were carried out with a HAAKE RheoStress RS600 from Thermo Electron Corp, while contact angles were evaluated with a Drop Shape Analyzer DSA 100 from KRÜSS. The water content of the solutions is also critical for the deposition and final properties of the samples; therefore, it was evaluated using the Karl-Fischer titration method. ${ }^{45}$ All solutions have water percentages after the synthesis of $\sim 0.7 \%$ wt.

Drop-on-Demand Inkjet Printing of REBCO Inks. Drop-ondemand piezoelectric inkjet printing (DoD IJP) from Microdrop Technologies $\mathrm{GmbH}$ was used to fabricate combinatorial test pieces on single-crystal (001) $\mathrm{SrTiO}_{3}$ (STO) substrates. Prior to deposition, the substrates were thermally treated at $900{ }^{\circ} \mathrm{C}$ for $5 \mathrm{~h}$ to develop a flat-terraced surface and thoroughly cleaned with acetone and methanol to remove any residues.

The IJP system possesses a 96-well plastic plate array that serves as solution containers. Each of the nozzles takes the solution from one of these vessels, which in our case contained YBCO and GdBCO precursor solutions. A multinozzle head was used to load each solution on separated nozzles (Figure 1a), and the ejection parameters (voltage and pulse length) were adjusted to achieve a stable drop formation, a drop diameter of $\sim 70 \mu \mathrm{m}$, and a drop volume of $\sim 180 \mathrm{pl}$ (Figure $1 \mathrm{~b}$ ). Throughout this article, only two nozzles/ inks were used to fabricate the combinatorial samples. The specific

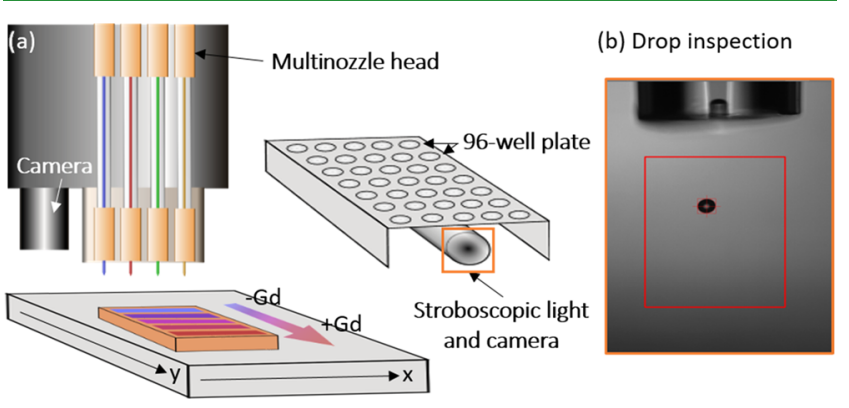

Figure 1. (a) DoD IJP setup, consisting of a 96-well plate array, a multinozzle head with four independent nozzles, a stroboscopic light/ camera for drop inspection, and a camera for surface inspection. (b) Captured in-flight image drop after the adjustment of the deposition parameters from the camera used for drop inspection. 
Table 1. Physicochemical Parameters of the REBCO Inks

\begin{tabular}{cccccc} 
\% vol EA & viscosity $(\mathrm{cP})$ & contact angle $(\mathrm{deg})$ & density $\left(\mathrm{g} / \mathrm{cm}^{3}\right)$ & surface tension $(\mathrm{mN} / \mathrm{m})$ & ejectability \\
0 & $5.0 \pm 0.1$ & $10.0 \pm 0.1$ & $0.98 \pm 0.01$ & $24.4 \pm 0.1$ & $9.2 \pm 0.1$ \\
1.14 & $6.8 \pm 0.1$ & $<10.0 \pm 0.1$ & $0.99 \pm 0.01$ & $25.4 \pm 0.1$ & ejectable \\
3.66 & $15.2 \pm 0.1$ & $<10.0 \pm 0.1$ & $0.99 \pm 0.01$ & $25.8 \pm 0.1$ & ejectable \\
\hline
\end{tabular}

printing positions were automatically generated through a Python interface that outputs an $(x, y)$-coordinate file with the desired pattern dimensions and drop/line pitches.

Sample Drying, Pyrolysis, and High-Temperature Annealing. After the deposition of the desired patterns, samples were dried at $60{ }^{\circ} \mathrm{C}$ to partially evaporate solvent leftovers and avoid further liquid movement. Subsequently, a pyrolysis procedure is performed in a tubular furnace at a heating rate of $5{ }^{\circ} \mathrm{C} / \mathrm{min}$ up to $240{ }^{\circ} \mathrm{C}$ and 3 ${ }^{\circ} \mathrm{C} / \mathrm{min}$ up to $500{ }^{\circ} \mathrm{C}$ in a humid oxygen flow of $0.12 \mathrm{l} \mathrm{O}_{2} / \mathrm{min}$ for 5 min. ${ }^{21}$ After pyrolysis, all of the organic materials have been removed from the sample and only amorphous/nanocrystalline phases remain. Finally, the combinatorial samples were treated at high temperatures under various conditions using a rapid thermal annealing furnace (Annealsys AS Micro) to grow the REBCO phases.

Sample Characterization. The characterization of combinatorial samples was performed using different techniques. Surface morphology of the as-deposited and pyrolyzed samples was evaluated by means of optical microscopy (OM) (Leica DM1750 M), as well as profilometry (P16+ profilometer from KLA Tencor), while scanning electron microscopy (SEM) with a QUANTA FEI 200 FEG-ESEM was employed to evaluate the surface morphology of grown samples.

Energy-dispersive X-ray (EDX) spectroscopy measurements were carried out on each stripe to verify the deposited composition and ensure an adequate merging of the REBCO inks.

The structural characterization was conducted by high-resolution X-ray diffraction (XRD) with a Bruker D8 Discover system $(\mathrm{Cu} \mathrm{K} \alpha$, $\mathrm{X}$-ray energy $=8.049 \mathrm{keV}$ ) equipped with a Lynxeye $\mathrm{XE}$ energydispersive one-dimensional (1D) detector. The quantification of the amount of epitaxial material on each stripe was performed using a Bruker-AXS D8 Advance diffractometer $(\mathrm{Cu} \mathrm{K} \alpha$ ) equipped with a general area detector diffraction system (GADDS).

The spatial distribution, size, and crystalline state of precursor phases in pyrolyzed films were probed via high-resolution transmission electron microscopy (HR-TEM) and high-angle annular dark-field scanning transmission electron microscopy (STEMHAADF). For this purpose, an FEI Tecnai F20 (S)TEM was operated at $200 \mathrm{kV}$. For transmission electron microscopy (TEM) studies, cross-sectional specimens were prepared by conventional methods: slicing, gluing, tripod mechanical polishing, and finally $\mathrm{Ar}+$ ion milling using Gatan PIPS.

In Situ XRD Synchrotron Measurements. In situ XRD growth experiments were performed at the DiffAbs beamline, SOLEIL synchrotron facilities (France), using an X-ray beam energy of $18 \mathrm{keV}$ and an XPAD (X-ray hybrid pixel area detector $)^{46,47}$ area detector with acquisition times per image of $100 \mathrm{~ms}$. The obtained images can be converted into intensity vs $2 \theta$ diffractograms considering the experimental geometry (sample and detector angular positioning) and using a home-written Python code. The samples were heat treated in an Anton Paar DHS 1100 domed heating stage at rates of $25^{\circ} \mathrm{C} / \mathrm{min}$, 1 bar of total pressure and 1 mbar of oxygen partial pressure. An X-ray transparent Kapton dome, equipped with a double connection to the vacuum pumps and gas inlet/outlet systems, was utilized to seal the heating stage. The total pressure control was achieved through electrovalves, while an oxygen sensor was used to preset $\mathrm{PO}_{2}$ at the desired value. Pressure values were tracked via the LabVIEW interface using a remote connection to a pressure meter. Synchrotron experiments were employed for the in situ analysis of the growth of combinatorial samples, as it will be described in the In Situ XRD Synchrotron Analysis section.

\section{RESULTS AND DISCUSSION}

The combinatorial chemistry approach aims to improve and speed up the fabrication of materials using high-throughput deposition and characterization techniques, as well as incorporating computational methods for the automation of data acquisition and processing. In this manuscript, we have studied the combinatorial approach through gradual compositional changes of the rare earth $(\mathrm{RE}=\mathrm{Y}, \mathrm{Gd})$ in the REBCO phase. It is worth noting that we will refer to the final $\mathrm{Y}_{1-x} \mathrm{Gd}_{x} \mathrm{BCO}$ composition throughout the manuscript even when talking about precursor inks and deposited stripes to classify the different compositions. Three stages have been considered in the combinatorial DoD IJP approach for the investigation of these REBCO superconductors: (1) determination of ink and deposition parameters for the deposition of combinatorial test pieces, (2) validation of the compositional homogeneity needed for combinatorial tests, and (3) identification of high-throughput characterization and data analysis of combinatorial test samples to extract valuable information of growth mechanisms.

Inkjet Printing Deposition Requirements. The use of DoD IJP to deposit combinatorial samples requires control of process parameters to ensure a uniform deposition, especially when combining several inks and nozzles. First of all, ink formulation, drop formation, jetting parameters, and drop pitches (spacing along the $x$ - and $y$-directions) need to be optimized. These variables are largely influenced by ink stability, as well as its physicochemical properties. Figure S1 shows the viscosity and surface tension measurements for the REBCO ink with $3.66 \%$ vol EA. The inverse Ohnesorge number $(Z)$ is often used as an indication of ink ejectability factor and is expressed as

$$
Z=\frac{\sqrt{\rho l \gamma}}{\eta}
$$

$\rho$ is the density of the liquid, $\eta$ is the viscosity, $\gamma$ is the surface tension, and $l$ is the nozzle diameter $(50 \mu \mathrm{m})$. Typical $Z$ values ensuring good ejectability range from minimum values of $1-4$ and maximum ones of $10-14 .^{48,49}$ Typical values for the tested REBCO inks are summarized in Table 1 . The inks employed in this work could be ejected for $Z>3.1$.

The optimized parameters employed in this work to achieve stable drop formation are summarized in Table 2. Typically, an increase in the \% vol EA required higher voltages to achieve a stable drop formation. Liu et al. mentioned that drop formation is achieved when the velocity is high enough to overcome the surface tension and viscous forces, ${ }^{50}$ which supports our observations for both types of inks.

The combinatorial test samples under the present study are composed of several stripes of different compositions deposited in one single sample. This geometry has enabled us to verify the methodology employed, as described below, and will allow us to extend it to more complex schemes (i.e., graded samples) in the future. To define the combinatorial chemistry strategy for inkjet printing, two precursor inks for 
Table 2. Jetting Parameters Employed for the Drop Formation (df) and Data Grid (dg) Deposition of REBCO Inks

\begin{tabular}{ll}
\multicolumn{1}{c}{ jetting parameters } & \multicolumn{1}{c}{ value } \\
voltage up $(\mathrm{V})$ & $140 \pm 40$ \\
voltage down $(\mathrm{V})$ & 0 \\
pulse length $(\mu \mathrm{s})$ & $25 \pm 5$ \\
substrate temperature $\left({ }^{\circ} \mathrm{C}\right)$ & $25 \pm 1$ \\
frequency $(\mathrm{Hz})$ & $1(\mathrm{dg}), 100(\mathrm{df})$ \\
drop volume $(\mathrm{pl})$ & $175 \pm 5$ \\
drop size $(\mu \mathrm{m})$ & $215 \pm 15(\mathrm{dg}), 70 \pm 2(\mathrm{df})$ \\
substrate $/ \mathrm{nozzle} \mathrm{distance}(\mathrm{mm})$ & $1.0 \pm 0.1$ \\
drop velocity $(\mathrm{m} / \mathrm{s})$ & $2.0 \pm 0.1$
\end{tabular}

YBCO and GdBCO final compositions were loaded into two separate nozzles. These inks were tested to print 5 stripes with $\mathrm{Y}_{1-x} \mathrm{Gd}_{x} \mathrm{BCO}$ ratio combinations of $x=0,0.25,0.5,0.75$, and 1 on single STO substrates. Single solvent inks are usually preferred since the evaporation rate plays a big role in the homogeneity of printed patterns. ${ }^{51}$ Despite this, the inks employed in this work contained both PPA and $\mathrm{BuOH}$ since the addition of $\mathrm{BuOH}$ provided thickness in the required range and provided an adequate boiling point to ensure a compatible drying process. ${ }^{52}$

The identification of the best drop pitch combinations is essential to ensure a homogeneous deposition of the different $\mathrm{Y}_{1-x} \mathrm{Gd}_{x} \mathrm{BCO}$ stripes. An average drop size of $241 \pm 4 \mu \mathrm{m}$ was obtained after measuring the diameter of several drops deposited on single-crystalline (001) STO substrates with a separation of $500 \mu \mathrm{m}$ between them (Figure S2a). The experimental testing of different drop pitches $(\mathrm{d} x=50,75$, and $100 \mu \mathrm{m}$ and $\mathrm{d} y=50,75,100,125$, and $250 \mu \mathrm{m})$ was then performed to fine-tune the best deposition conditions (Figure S2b). Small drop pitches ( $50 \mu \mathrm{m} \times 50 \mu \mathrm{m}$ and $75 \mu \mathrm{m} \times 75$ $\mu \mathrm{m})$ showed a large accumulation of solution, which led to inhomogeneities due to liquid movement, while larger combinations led to unconnected patterns. The conditions that showed very little liquid movement and smooth surfaces were $\mathrm{d} x=50 \mu \mathrm{m}$ and $\mathrm{d} y=85-100 \mu \mathrm{m}$. These drop pitches result in degrees of overlap in $x=80 \%$ and $y=60 \%$ (100 $\mu \mathrm{m})-65 \%(85 \mu \mathrm{m})$. The degree of overlap was calculated using the expression $\frac{O}{D} \times 100$, where $O$ is the overlapping distance between the two drops $(D-\mathrm{d} x$ or $D-\mathrm{d} y)$ and $D$ is the diameter of the drop impact.

We have also explored the inclusion of additives in ink to enhance the solubility of the metalorganic precursors, increase the homogeneity, facilitate drop formation, as well as to prevent excessive drying of solvents and nozzle clogging. ${ }^{53,54}$ In particular, we used ethanolamine (EA) for its known role as a complexing agent in copper-based solutions. ${ }^{55}$ Several $\%_{v / v}$ EA were tested to find a compromise between the increase of ink viscosity with the amount of EA (Table 1) and the increased difficulty for drop ejection. The optimized solution contained a $1 \%_{\mathrm{v} / \mathrm{v}}$ EA and a 50/50 PPA/BuOH ratio. Figure 2 shows two combinatorial samples prepared with inks containing $0 \% \mathrm{v} / \mathrm{v}$ and $1 \% \%_{\mathrm{v} / \mathrm{v}} \mathrm{EA}$ and a $50 / 50 \mathrm{PPA} / \mathrm{BuOH}$ ratio in a $0.75 \mathrm{M}$ solution with RE-prop, Ba-prop, and $\mathrm{Cu}(\mathrm{ac})_{2}$ metalorganic salts. The addition of EA clearly shows a qualitative improvement in the homogeneity of the printed stripes, liquid movement is greatly reduced, and the stripe edges are better confined into the printed dimensions $(500 \mu \mathrm{m} \times 5 \mathrm{~mm})$.

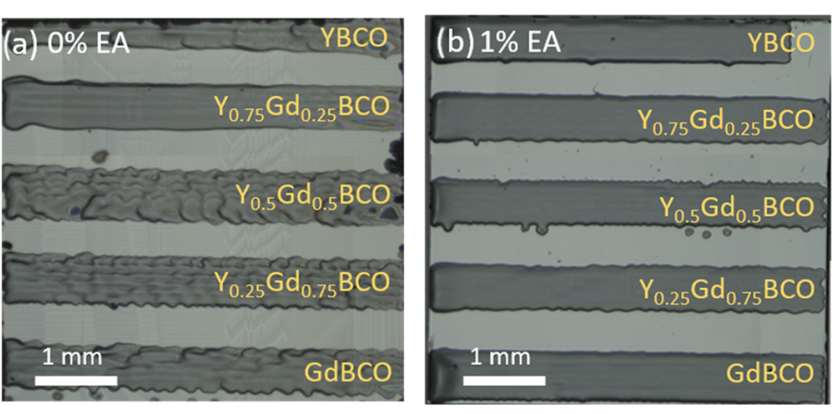

Figure 2. OM images of the as-deposited combinatorial samples showing the stripe morphology for inks with a 50/50 ratio of PPA/ $\mathrm{BuOH}$, and containing (a) $0 \%$ and (b) $1 \%$ of EA. Drop pitches of 50 $\mu \mathrm{m}$ and $95 \mu \mathrm{m}$ along the $x$ - and $y$-directions were employed.

To optimize the pyrolysis conditions of combinatorial samples, at first, a complete film with a nominal $\mathrm{Y}_{1-x} \mathrm{Gd}_{x} \mathrm{BCO}$ ratio of $x=0$ was prepared by spin-coating with a subsequent thermal treatment $\left(5^{\circ} \mathrm{C} / \mathrm{min}\right.$ up to $240{ }^{\circ} \mathrm{C}$ and at $3{ }^{\circ} \mathrm{C} / \mathrm{min}$ from 240 to $500{ }^{\circ} \mathrm{C}$ ). This ensured the decomposition of the organic constituents and the formation of nanocrystalline oxycarbonates $\left(\mathrm{RE}_{2} \mathrm{O}_{3}, \mathrm{BaCO}_{3}\right.$, and $\left.\mathrm{CuO}\right)$, which are the precursor phases for the REBCO final layer to be reached upon an additional second high-temperature treatment. ${ }^{56}$ TEM investigations were conducted on this sample to evaluate the intermediate precursor phases present after the pyrolysis step. The low-magnification STEM-HAADF image of an aspyrolyzed YBCO film (Figure 3a) reveals a film thickness of $\sim 800 \mathrm{~nm}$, and nanocrystalline phases are homogeneously distributed within the film. It has been found that any coarsening or phase segregations, for example, $\mathrm{CuO}$ segregation at the interface of multiple layers, can degrade the film quality and homogeneity of the grown REBCO thin film. ${ }^{55}$ In this regard, the above-pyrolyzed film, without the presence of any segregation layer, as displayed in Figure 3a, can provide a high-quality REBCO grown film. We expect that the decomposition of $\mathrm{YBCO}$ and $\mathrm{GdBCO}$ precursor solutions will occur similarly since thermogravimetric studies have been performed previously on YBCO precursor films by Rasi et al. ${ }^{56}$ showing that all organic precursor transformations occur below $500{ }^{\circ} \mathrm{C}$, and at that temperature only $\mathrm{Y}_{2} \mathrm{O}_{3}, \mathrm{CuO}$, and $\mathrm{BaCO}_{3}$ remain in the films. Additionally, Grivel et al. ${ }^{57}$ have investigated the decomposition of different rare earth propionate powder precursors, including gadolinium propionate. They observed that all rare earth propionate precursors behave similarly, leading to amorphous nanocrystalline oxide phases at $500{ }^{\circ} \mathrm{C}$. It is worth noting that films decompose earlier than powders due to the much more efficient gas transport occurring in the films as compared to powders as reported previously. ${ }^{58}$ The low-magnification STEM-HAADF image in the bottom-right inset of Figure 3a displays the smooth surface of the as-pyrolyzed YBCO thin film. The distinct nanocrystalline phases are identified in HR-TEM images (Figure $3 \mathrm{~b}-\mathrm{e}$ ), which show the typical diameters of $\mathrm{BaCO}_{3}$ (orthorhombic), 10-30 nm; $\mathrm{BaCO}_{3}$ (monoclinic), 5$7 \mathrm{~nm}$; $\mathrm{CuO}, 10-25 \mathrm{~nm}$; and $\mathrm{Y}_{2} \mathrm{O}_{3}, 5-6 \mathrm{~nm}$. The majority of $\mathrm{BaCO}_{3}$ is found to be orthorhombic that can easily decompose during the TLAG-CSD process. ${ }^{56}$ Moreover, the size of nanocrystalline phases of about tens of nanometers can also assist in the fast reaction process during the TLAG-CSD growth. The HR-TEM image in Figure $3 \mathrm{f}$ exhibits high homogeneity among nanocrystalline phases of $\mathrm{BaCO}_{3}$ 

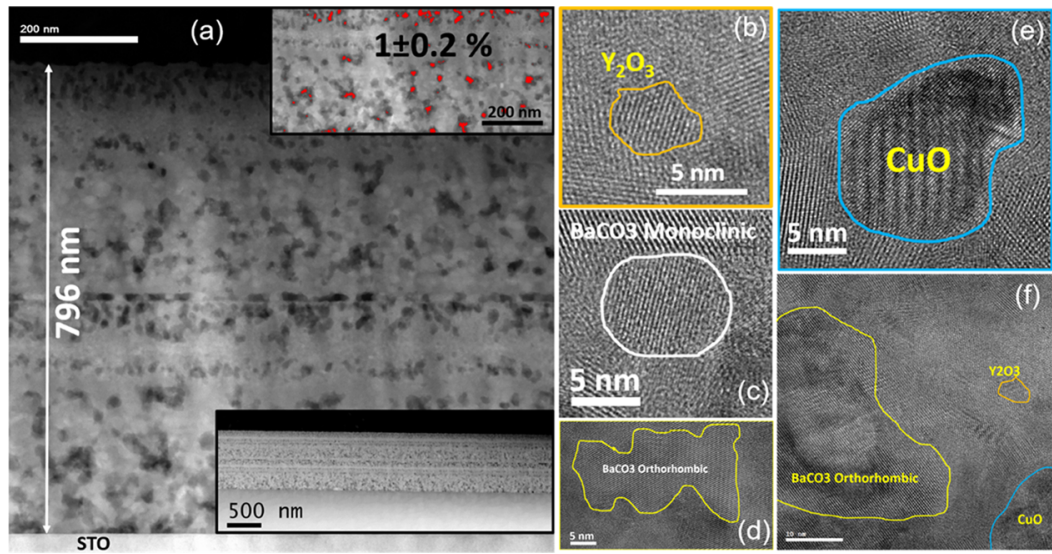

Figure 3. (a) STEM-HAADF image of the as-pyrolyzed film, where $\mathrm{CuO}$ nanocrystals (in gray) are homogeneously distributed within a $\mathrm{BaCO}_{3}$ (white) matrix. The inset (top-right) shows the porosity analysis, where pores are colored in red for quantification. The inset (bottom-right) is a low-magnification cross-sectional STEM-HAADF image exhibiting the smooth surface of the thin film. (b-e) HR-TEM images identify the distinct nanocrystalline phases of $\mathrm{Y}_{2} \mathrm{O}_{3}, \mathrm{BaCO}_{3}$ (monoclinic), $\mathrm{BaCO}_{3}$ (orthorhombic), and $\mathrm{CuO}$, respectively. (f) HR-TEM image shows the presence of all three nanocrystalline phases in the same region, exhibiting a homogeneous distribution.
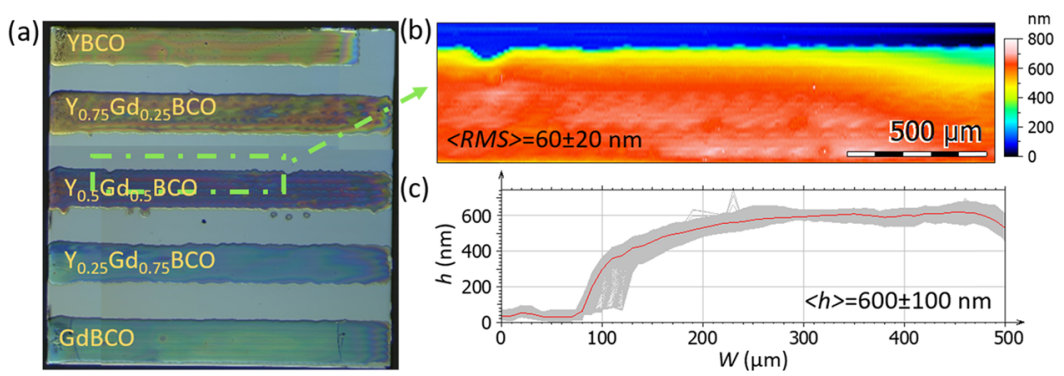

Figure 4. (a) OM images of a pyrolyzed combinatorial sample with different REBCO (RE = Y, Gd) compositions as indicated. (b) 3D profilometry surface map of a stripe with a 50/50 composition. (c) Series of profiles (gray lines) and the mean value (red line) extracted from the green region in (b). The roughness mean square (RMS) value and average height $(\mathrm{h})$ have been calculated from different stripes and samples.

(orthorhombic), $\mathrm{Y}_{2} \mathrm{O}_{3}$, and $\mathrm{CuO}$, which was also confirmed throughout the film from the HR-TEM observation of randomly chosen regions of several films. The pore density of the film was calculated using image analysis (ImageJ), and it is estimated to be approximately $1.0 \pm 0.2 \%$, as shown in the top-right inset of Figure 3a. We emphasize that the degree of porosity is remarkably low, especially for pyrolyzed CSD films, and expected to enable improved epitaxial growth of REBCO in the final step of crystallization. ${ }^{55}$ We believe that the addition of EA might be the origin of this reduced porosity and we are currently conducting several studies to confirm it.

Since the only change between the different compositions is related to the $\mathrm{RE}_{2} \mathrm{O}_{3}$ phase, combinatorial samples were printed with the optimized conditions and, subsequently, subjected to the previously described pyrolysis treatment. Figure 4a shows a pyrolyzed combinatorial sample with stripes that contain nominal $\mathrm{Y}_{1-x} \mathrm{Gd}_{x} \mathrm{BCO}$ ratios ranging from $x=0$ (YBCO) to $x=1$ ( $\mathrm{GdBCO})$ as indicated. The average roughness mean square (RMS) roughness, which was calculated from three-dimensional (3D) profilometry images of the stripe surface on several stripes (Figure $4 \mathrm{~b}$ ), is $60 \pm 20$ $\mathrm{nm}$. A series of profiles extracted along the width of each stripe (Figure 4c) show that the edges are highly defined, with less than $50 \mu \mathrm{m}$ difference between the start to the end. In addition, while the height of each stripe is very homogeneous, an average value of $600 \pm 100 \mathrm{~nm}$ has been calculated from several measurements on different stripes.
Compositional Homogeneity Validation for Combinatorial Samples. Drop positions and solution intermixing, upon deposition, are key parameters to define combinatorial patterns (discrete or gradient type) by DoD IJP. In our case, we selected a set of five equally separated stripes of different compositions. The validation of the composition homogeneity within one stripe is essential to demonstrate the capabilities of stoichiometry tuning. Figure 5 shows the visual representation of the printing positions and drop overlapping, considering a drop diameter of $240 \mu \mathrm{m}$ and a grid size of $50 \mu \mathrm{m} \times 95 \mu \mathrm{m}$. These visualizations were generated from data obtained using a self-made Python interface, as well as employing the NumPy, Pandas, and Matplotlib libraries. ${ }^{59-61}$ The schematic representation of the drop combinations between the two inks used for each composition is also illustrated on the right side. This suggests that the previously determined experimental conditions should enable a high degree of solution intermixing and a uniform composition distribution along the printed stripes given that the same miscible solvents are employed for all solutions. It also reveals that the pattern edges may present a less uniform distribution due to edge constrains.

Screening over a large number of samples is one of the main aspects that must be addressed when dealing with combinatorial samples to promote the construction of material libraries. Among the different techniques available, it is required that they possess sufficient spatial precision and resolution, as well as acquisition speed, and allow parallel or rapid sequential analysis. ${ }^{25,62,63}$ With this in mind, several 


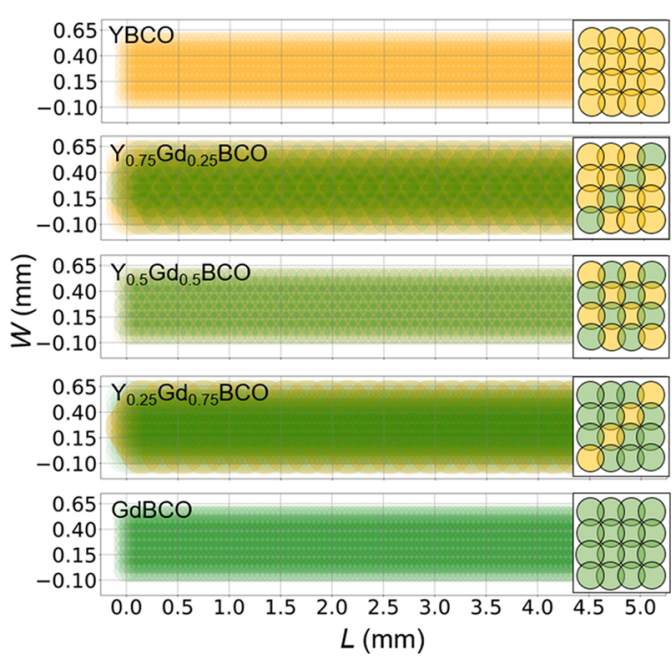

Figure 5. Plots that illustrate the printed DoD IJP patterns for $\mathrm{Y}_{1-x} \mathrm{Gd}_{x} \mathrm{BCO}$ composition ratios of (a) $x=0$, (b) 0.25 , (c) 0.5 , (d) 0.75 , and (e) 1 , with a grid size of $50 \mu \mathrm{m} \times 95 \mu \mathrm{m}$. The $(x, y)$ coordinates were automatically generated using a self-made Python interface. The graphs on the right side of each stripe show a schematic representation of the drop alternation between the two inks used to reach the desired composition. Yellow and green indicate the drops of the two different solutions used.

techniques have been employed to evaluate the composition of combinatorial samples such as X-ray fluorescence, energydispersive X-ray spectroscopy (EDX), X-ray diffraction, mass spectrometry, etc. ${ }^{26,27,64}$ In our study, we used EDX for several combinatorial samples to evaluate the composition accuracy of each stripe and validate the DoD IJP approach. Figure 6a shows the elemental analysis performed by EDX of a typical area of approximately $250 \mu \mathrm{m} \times 250 \mu \mathrm{m}$, where the acquisition was conducted for a stripe with $\mathrm{Y}_{0.5} \mathrm{Gd}_{0.5} \mathrm{BCO}$. It should be recalled that the drop size was of $241 \pm 4 \mu \mathrm{m}$ in diameter and the drop pitches were $\mathrm{d} x=50 \mu \mathrm{m}$ and $\mathrm{d} y=85-100 \mu \mathrm{m}$, which should ensure $60-80 \%$ drop overlap (Figure 5). Figure S3 shows the EDX elemental analysis and SEM images of selected areas from stripes with $\mathrm{Y}_{1-x} \mathrm{Gd}_{x} \mathrm{BCO}$ compositions of $\mathrm{x}=0.25$ and 0.75 . After the measurement of several stripes, we performed a statistical analysis that shows the average values obtained and their standard deviation for each theoretically desired composition (Figure $6 \mathrm{~b}$ ). Focusing on compositions with different percentages of $\mathrm{Y}_{1-x} \mathrm{Gd}_{x} \mathrm{BCO}$ inks, we confirm, on samples annealed at $5{ }^{\circ} \mathrm{C} / \mathrm{s}$ up to 815 and $830{ }^{\circ} \mathrm{C}$ for 2 $\mathrm{min}$, that the desired composition values and measured ones do not deviate much from each other. Nevertheless, there is a slightly large dispersion of values with a maximum variation of $\pm 15 \%$ for different samples with $\mathrm{Y}_{0.5} \mathrm{Gd}_{0.5} \mathrm{BCO}$, which might be influenced by the fact that growth at 50/50 was the most complicated over the full range explored.

The evaluation of the $c$-axis lattice parameter for REBCO has been employed as another indicator to demonstrate proper $\mathrm{RE}$ mixing on the scale of a unit cell. Considering that $\mathrm{Y}_{1-x} \mathrm{Gd}_{x} \mathrm{Ba}_{2} \mathrm{Cu}_{3} \mathrm{O}_{7}$ is a solid solution in $\mathrm{RE}$, the lattice parameter of each composition should be a weighted mean, according to their ratio in the sample. ${ }^{65}$ Following this description, high-resolution XRD was conducted (Figure 7). To minimize systematical errors, substrate alignment was carried out individually for each stripe prior to the measurement (using the STO (200) reflection at $2 \theta=46.47^{\circ}$ ). The $c$ axis parameter of each composition was then determined by
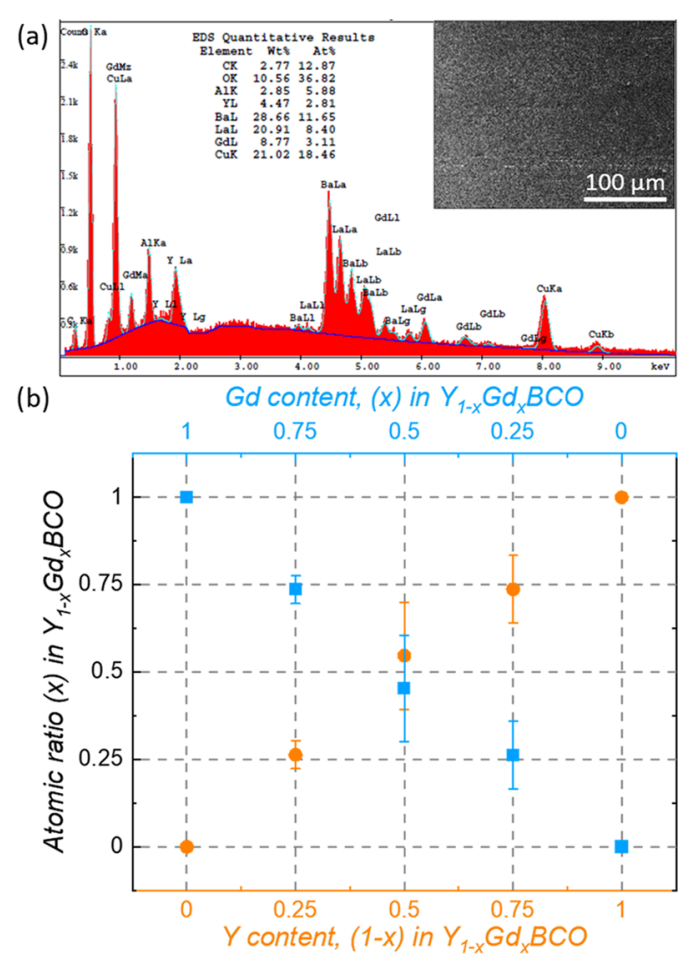

Figure 6. (a) EDX elemental analysis of selected area from a stripe with a $\mathrm{Y}_{0.5} \mathrm{Gd}_{0.5} \mathrm{BCO}$. The inset shows the SEM image of the measured region. (b) Statistical analysis of the composition measured by performing EDX spectroscopy on several combinatorial samples with stripes having $\mathrm{Y}_{1-x} \mathrm{Gd}_{x} \mathrm{BCO}$ ratios of $x=0,0.25,0.5,0.75$, and 1 .
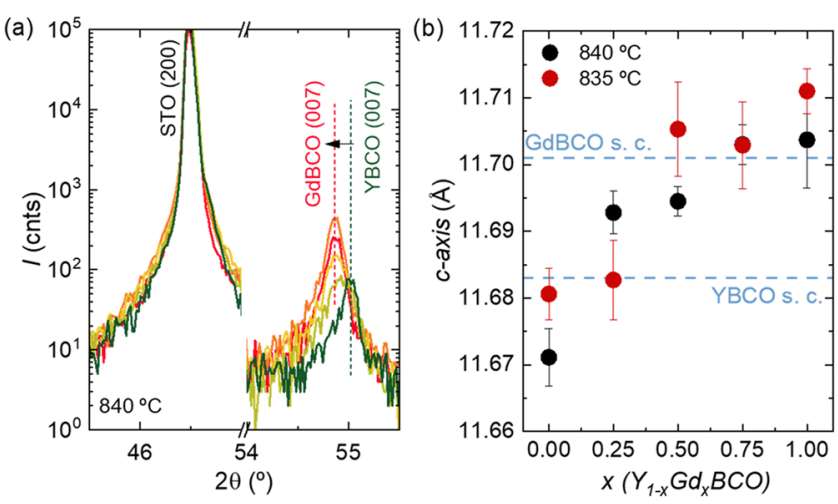

Figure 7. (a) High-resolution XRD diffractograms of a sample annealed at $5{ }^{\circ} \mathrm{C} / \mathrm{s}, 840{ }^{\circ} \mathrm{C}$ for $2 \mathrm{~min}$ and a $\mathrm{PO}_{2}$ of $1 \mathrm{mbar}$, depicting the (200) STO substrate peak position and the (007) peak for each $\mathrm{Y}_{1-x} \mathrm{Gd}_{x} \mathrm{BCO}$ composition. (b) Evolution of the $c$-axis parameter for $\mathrm{Y}_{1-x} \mathrm{Gd}_{x} \mathrm{BCO}$ samples annealed at $5{ }^{\circ} \mathrm{C} / \mathrm{s}$ up to $835^{\circ} \mathrm{C}$ and $840{ }^{\circ} \mathrm{C}$

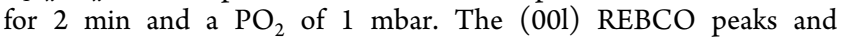
associated shifts, as shown in (a), are translated into lattice parameter variations using the Nelson-Riley criteria (Figure S4). Blue lines indicate the theoretical values from the ICSD database, 11.701 and $11.683 \AA$ for the optimally doped GdBCO and YBCO. Error bars are obtained from the Nelson-Riley linear regression.

fitting of (00l) REBCO peaks, $l \geq 5$, with pseudo-Voigt profiles and extrapolating to $x=0$ following the Nelson-Riley criteria (Figure S4) ${ }^{66}$

$$
\frac{1}{2}\left(\frac{\cos ^{2} \theta}{\sin \theta}+\frac{\cos ^{2} \theta}{\theta}\right)
$$


Figure 7a shows the XRD diffractograms of the (200) STO peak together with the (007) reflection of each $\mathrm{Y}_{1-x} \mathrm{Gd}_{x} \mathrm{BCO}$ composition, used for the calculation of the $c$-axis lattice parameter of each stripe for a sample annealed at $5{ }^{\circ} \mathrm{C} / \mathrm{s}$ up to $840{ }^{\circ} \mathrm{C}$ for $2 \mathrm{~min}$. Figure $7 \mathrm{~b}$ illustrates the evolution of the $\mathrm{c}$ axis lattice parameter as a function of the $\mathrm{Y}_{1-x} \mathrm{Gd}_{x} \mathrm{BCO}$ ratio for two samples annealed at $5{ }^{\circ} \mathrm{C} / \mathrm{s}$ up to $835^{\circ} \mathrm{C}$ and $840{ }^{\circ} \mathrm{C}$ for $2 \mathrm{~min}$. The trend depicted for each stripe is clearly in agreement with those obtained for the optimally doped YBCO and GdBCO for single crystals, which have $c$-axis parameters of 11.683 and $11.701 \AA$, respectively.

Identification of High-Throughput Characterization and Data Analysis. Assessment of Epitaxial Growth Conditions. The validation of the combinatorial approach presented above now allows us to explore the differences in growth conditions for $\mathrm{Y}_{1-x} \mathrm{Gd}_{x} \mathrm{BCO}$ by investigating several stripes at the same time. Several sets of combinatorial samples were grown following the temperature route of the REBCO TLAG-CSD approach ${ }^{21}$ at temperatures ranging from 750 to $850{ }^{\circ} \mathrm{C}$ with 2 min of dwell and a heating ramp of $5{ }^{\circ} \mathrm{C} / \mathrm{s}$. Our goal was to assess the degree of epitaxy at each condition to establish the optimum growth temperature for each composition. Figure 8 shows a composition vs temperature

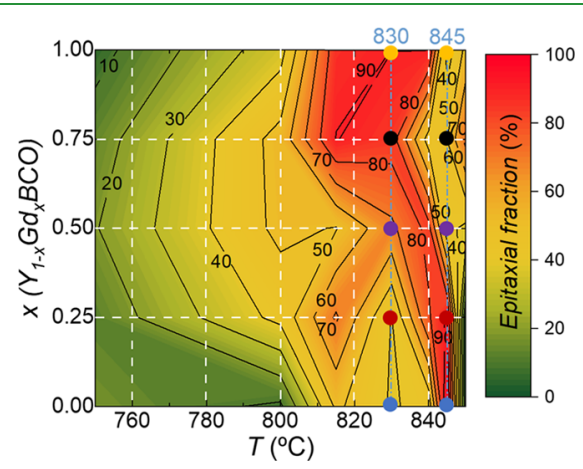

Figure 8. Three-dimensional (3D) map of the epitaxial fraction as a function of the $\mathrm{Y}_{1-x} \mathrm{Gd}_{x} \mathrm{BCO}$ composition and temperature for samples annealed at $5{ }^{\circ} \mathrm{C} / \mathrm{s}$ for $2 \mathrm{~min}$ and a $\mathrm{PO}_{2}$ of $1 \mathrm{mbar}$. The colored dots indicate the SEM images of specific $\mathrm{Y}_{1-x} \mathrm{Gd}_{x} \mathrm{BCO}$ composition, depicted in Figure S6 (Supporting Information) for two samples annealed at $5{ }^{\circ} \mathrm{C} / \mathrm{s}$ up to 830 and $845^{\circ} \mathrm{C}$ for $2 \mathrm{~min}$ and a $\mathrm{PO}_{2}$ of 1 mbar, as indicated in the figure.

map with the degree of epitaxy as the color scale. The epitaxial fraction was calculated by integrating two-dimensional (2D)XRD $2 \theta-\chi$ scans at the position of the (005)REBCO reflection at $\chi=0^{\circ}\left(I_{\text {ep }}^{\exp }\right)$ and $\chi \neq 0^{\circ}\left(I_{\text {ring }}^{\text {exp }}\right)$, as indicated in Figure S5. Then, the relationship between the epitaxial
$\left(I_{\text {epitaxial }}\right)$ and polycrystalline $\left(I_{\text {random }}\right)$ orientations is quantified with the following equations ${ }^{67}$

$$
\begin{aligned}
& \frac{I_{\text {random }}}{I_{\text {epitaxial }}}=\frac{I_{\text {ring }}^{\text {exp }} \times(360 / \Delta \chi) \times 4 \pi}{8 \times I_{\text {epi }}^{\text {exp }}} \\
& I_{\text {random }}+I_{\text {epitaxial }}=100(\%)
\end{aligned}
$$

Below $800{ }^{\circ} \mathrm{C}$, the degree of epitaxy achieved increases with temperature from around $10-20 \%$ up to $50 \%$. A higher degree of epitaxy is observed for Gd-rich compositions. Full epitaxial growth $(>90 \%)$ is observed for the Gd-rich compositions $(x \geq$ 0.75 ) at temperatures between 815 and $830{ }^{\circ} \mathrm{C}$, while compositions with $x \leq 0.5$ show values between 20 and $70 \%$. Above $830{ }^{\circ} \mathrm{C}$, the degree of epitaxy starts decreasing for Gd-rich samples, while Y-rich compositions reach epitaxy values above $90 \%$ at $845{ }^{\circ} \mathrm{C}$. Despite this, Gd-rich compositions show epitaxial fraction values between 40 and $70 \%$ up to $850{ }^{\circ} \mathrm{C}$, while Y-rich ones decrease much faster. Figure S6 shows the SEM images of the samples grown at 830 and $845{ }^{\circ} \mathrm{C}$. It confirms that $830{ }^{\circ} \mathrm{C}$ is a rather good temperature to achieve homogeneous, flat, and porous free layers for Gd-rich compositions, while higher temperatures have to be achieved for Y-rich ones. The evolution of the epitaxial fraction with temperature is related to the supersaturation of the $\mathrm{Ba}-\mathrm{Cu}-\mathrm{O}$ melt, advantageously used in the nonequilibrium TLAG-CSD process to enhance growth rates. In general, at low temperatures, crystallization occurs at higher supersaturation, while at high temperatures supersaturation decreases, enabling the $c$-axis heteroepitaxial growth to be achieved. In these liquid mediated processes, supersaturation is dominated by the concentration of RE dissolved in the liquid. As temperature increases, this should also increase provided the heating ramp does not limit this process. Nevertheless, the optimum conditions will be different for each composition, since relative supersaturation, $\Delta \sigma=\left(C_{\gamma} / C_{\mathrm{e}}-1\right)$, depends on the difference between the RE concentration in the liquid, $C_{\gamma}$ and equilibrium concentration, $C_{e}$, at each temperature and time. ${ }^{21}$ It is known that $C_{\mathrm{e}}$ depends on the RE, with $C_{\mathrm{e}, \mathrm{Gd}}>$ $C_{\mathrm{e}, \mathrm{Y}}{ }^{68}$ thus confirming that lower relative supersaturation conditions will likely be reached for $\mathrm{GdBCO}$ than for $\mathrm{YBCO}$ at a fixed temperature, though we cannot discard variation of $C_{\gamma}$ with RE. All of these arguments support the experimental evidence that the highest epitaxial degree is reached with $\mathrm{GdBCO}$ at $830{ }^{\circ} \mathrm{C}$, while it is at $845^{\circ} \mathrm{C}$ for YBCO. Overall, the combinatorial approach employed here has enabled to map epitaxial growth as a function of composition and temperature, demonstrating the desired reduction in the sample number through the combinatorial strategy (13 combinatorial samples
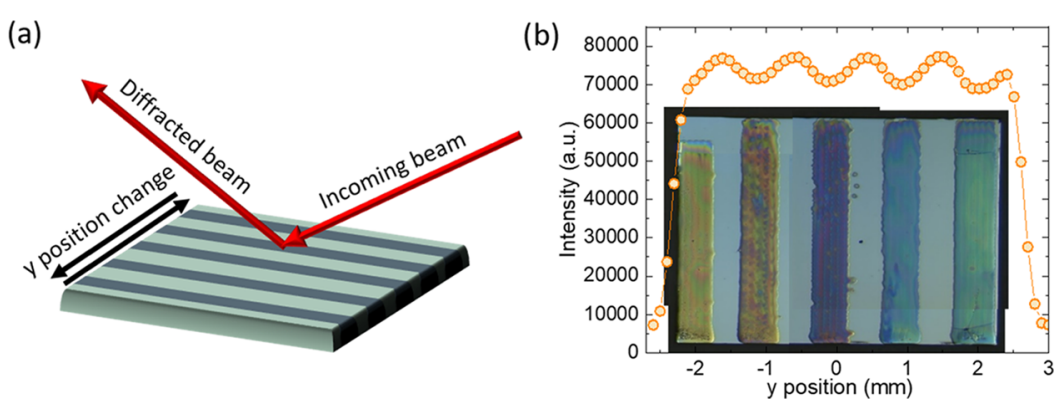

Figure 9. (a) Schematic representation of the experimental setup used for the in situ synchrotron measurements, and (b) beam alignment to determine the stripes' position, i.e., at the intensity minima. 

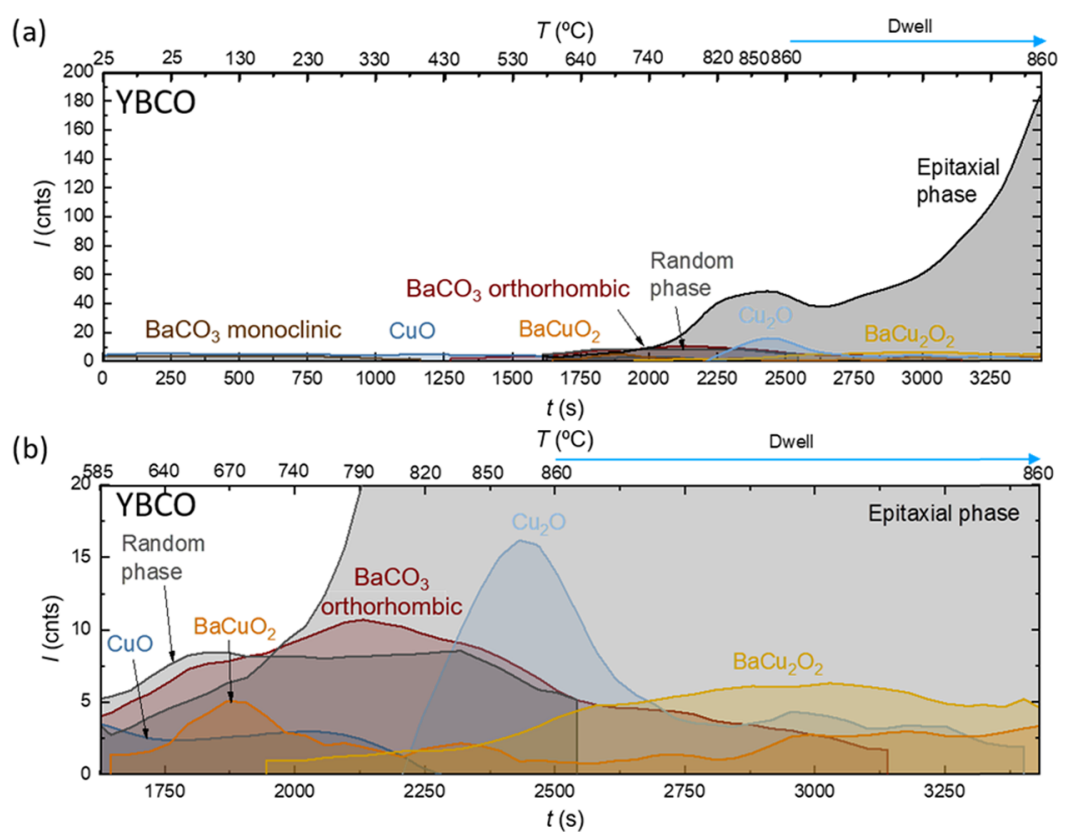

Figure 10. In situ XRD synchrotron measurements during annealing by heating at $25{ }^{\circ} \mathrm{C} / \mathrm{min}$ up to $860{ }^{\circ} \mathrm{C}$. Phase evolution of the YBCO stripe (a) showing the total diffraction intensity for each crystalline phase, and (b) zoom-in of (a) for better visualization of the low-intensity phases.
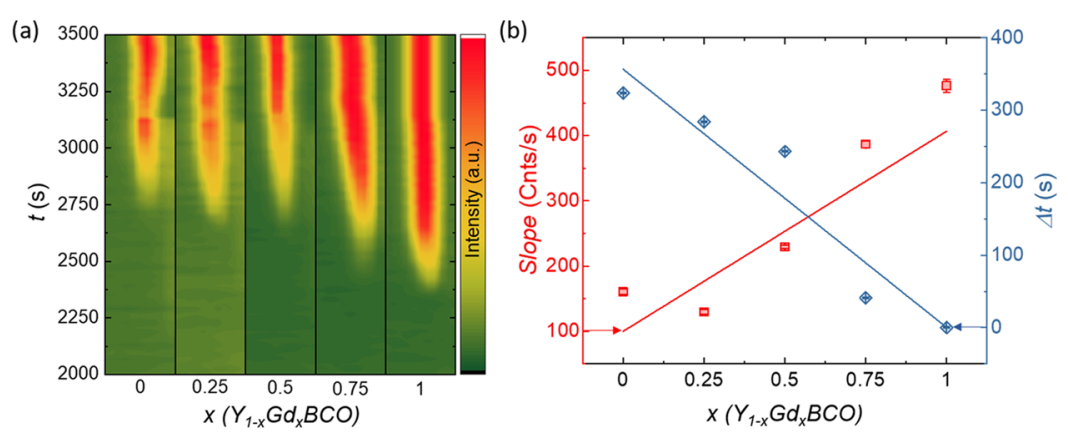

Figure 11. (a) Color map showing the time evolution of the intensity of the $(005)$ epitaxial peak $\left(2 \theta \sim 16.7-16.9^{\circ}\right)$, and $(\mathrm{b})$ intensity increase (slope) and time difference $(\Delta t)$ for crystallization of the epitaxial phase for stripes with $\mathrm{Y}_{1-x} \mathrm{Gd}_{x} \mathrm{BCO}$ ratios of $x=0,0.25,0.5,0.75$, and 1 , taking $t_{\mathrm{GdBCO}}$ as a reference. The error bars were determined from the difference between the points used to calculate the time where epitaxial crystallization begins.

instead of 78 regular samples were explored to reach the same mapping resolution).

In Situ XRD Synchrotron Analysis. Synchrotron radiation is a powerful tool for high-throughput experimentation, thanks to the high monochromaticity, brightness, collimation, and temporal/spatial resolution, allowing rapid characterization of microsized combinatorial samples. ${ }^{69,70}$ In addition, in situ experiments can be performed if fast $2 \mathrm{D}$ detectors are employed. In the case of the ultrafast TLAG-CSD growth process, this is the only way to explore the kinetically driven ultrafast growth mechanisms. Here, in situ XRD experiments were performed on our combinatorial samples using the setup described in the In Situ XRD Synchrotron Measurements section. The aim was to in situ analyze the 5 stripes localized in one single sample and in a single (same) growth process. Using an area detector, a certain $2 \theta$ angular range, of about $10^{\circ}$, is covered in a single shot/image. The sample and detector angles were fixed and set to record scattered signal close to the substrate and precursors diffraction peaks. The strategy followed was to measure the printed stripes through a "stopand-go" stage movement along the transverse $y$-direction, as schematically shown in Figure 9a. The position of each stripe was determined through a quick scan along the $y$-direction with a set of defined positions, and by evaluating the scattered intensity variations (around particular $2 \theta$ values) of the acquired XRD datasets vs the lateral position. In these conditions, the intensity minima indicate the center position of each stripe, while the peaks correspond to the substrate (Figure 9b). The movement time between stripes was estimated to be $1.6 \mathrm{~s}$ on average, considering the acquisition and data transfer times. It should also be noted that substrate positions between the stripes were also measured. Hence, a measurement was performed on each stripe every $\sim 20 \mathrm{~s}$, which are relatively long acquisition times. As a result, these set of experiments required the use of TLAG-CSD conditions where the growth process is relatively slow $(1-5 \mathrm{~nm} / \mathrm{s})$, using slower heating ramps as compared to the ones reported before. ${ }^{21,56}$ This approach allowed us, together with the combinatorial films, to resolve the REBCO crystallization process and intermediate reactions in time, temperature and $\mathrm{Y}_{1-x} \mathrm{Gd}_{x} \mathrm{BCO}$ compositions, all in one single experiment (Figure S7).

Figure 10 shows the phase evolution with time and temperature for an in situ XRD synchrotron experiment conducted during annealing by heating at a rate of $25^{\circ} \mathrm{C} / \mathrm{min}$ 
up to $860^{\circ} \mathrm{C}$. The phase evolution is extracted from $2 \mathrm{D}$-XRD raw data images consisting of $2 \theta, \chi$ and intensity information by performing a summation of counts in a particular $2 \theta-\chi$ area of each image and fitting of $I(2 \theta)$ peaks. Figure S8 shows a 2D-XRD raw image of a time frame, where the (005) and (103) REBCO phases coexisted. At temperatures below 400 ${ }^{\circ} \mathrm{C}$, typical intermediate precursor phases of $\mathrm{YBCO}$ fluorinefree precursor films are observed, ${ }^{21}$ i.e., $\mathrm{BaCO}_{3}$ (monoclinic) and $\mathrm{CuO}$. Above this temperature, the $\mathrm{BaCO}_{3}$ (monoclinic) phase transforms into $\mathrm{BaCO}_{3}$ (orthorhombic) and reacts with $\mathrm{CuO}$ to form the transient liquid. The observed $\mathrm{BaCuO}_{2} /$ $\mathrm{BaCu}_{2} \mathrm{O}_{2}$ and $\mathrm{Cu}_{2} \mathrm{O}$ phases crystallize from the liquid due to the heating rates of the experiment $\left(25^{\circ} \mathrm{C} / \mathrm{min}\right)$. The YBCO phase starts to form at around $600{ }^{\circ} \mathrm{C}$ and is mostly randomly oriented at this point. At only around $790{ }^{\circ} \mathrm{C}$, the epitaxial part is significantly increasing in intensity. It is noticeable that the random YBCO phase completely disappears at expenses of the epitaxial orientation at $860^{\circ} \mathrm{C}$. These experiments encouraged us to further study the mechanism behind this orientation conversion; the mechanisms will be reported elsewhere. Additional details on the influence of the heating ramp on the formation of intermediate precursor phases and YBCO are also of major importance and will be discussed in another publication since it goes beyond the scope of this work.

Figure 11a shows a color map with the evolution of the epitaxial phase (scattered intensity in the vicinity of the (005) peak), ${ }^{21}$ but adapted to the combinatorial strategy and the different REBCO compositions presented in this work. Note that the stripes possess different times for the initiation of epitaxial crystallization, depending on their composition, as identified in Figure $11 \mathrm{~b}$. In particular, the stripe with $100 \%$ GdBCO starts to crystallize first, the one with $100 \% \mathrm{YBCO}$ is the last $(\Delta t=324 \mathrm{~s})$, and the intermediate compositions lay between both individual REBCO phases, according to their RE proportion. In addition, the slope of the increase in intensity of the (005) epitaxial peak reveals two times faster rise for the GdBCO composition as compared to YBCO. These results are in accordance with previous reports, ${ }^{65}$ where the growth rate of REBCO materials in liquid-assisted methods was shown to be proportional to the solubility of the RE. Since the atomic radius of $\mathrm{Gd}$ is larger than that of $\mathrm{Y}$, its solubility will be higher and, hence, this could possibly explain its earlier crystallization as compared to $\mathrm{Y}$.

In summary, the work presented here demonstrates that screening over a large variety of conditions is facilitated by the fabrication of combinatorial samples. Appropriate characterization techniques have enabled simultaneous measurement of combinatorial samples, leading to the generation of a large volume of information to be analyzed and interpreted, which is vital in the implementation of a data-driven material design scheme based on "big data". Automation tools for data acquisition and treatment are also necessary to generate inputs for machine learning algorithms, which can be used to ease the interpretation of results, as well as enable the smart optimization of epitaxial growth conditions for different REBCO stoichiometries and, eventually, find the best functional properties.

\section{CONCLUSIONS AND OUTLOOK}

The potential of combinatorial and high-throughput experimentation for fast identification of the experimental conditions to grow different $\mathrm{Y}_{1-x} \mathrm{Gd}_{x} \mathrm{BCO}$ compositions by the TLAG-CSD approach has been demonstrated. Drop-on- demand inkjet printing was successfully used to deposit combinatorial samples in the form of stripes of different compositions, obtaining a homogeneous surface distribution during the pyrolysis step after the optimization of the ink composition and printing positions. The TEM microstructure analysis of a complete film revealed the homogeneous distribution of nanocrystalline phases and the low porosity of the pyrolyzed stripes. The desired compositions could be successfully implemented and confirmed through the combined use of computational methods and postcharacterization techniques such as EDX and HRXRD, as evidenced by elemental rare earth ratio and the c-parameter values. We have also shown that epitaxial growth conditions vary for each $\mathrm{Y}_{1-x} \mathrm{Gd}_{x} \mathrm{BCO}$ composition, Gd-rich ones having higher values of an epitaxial fraction at lower temperatures as compared to $\mathrm{Y}$ rich ones. Finally, in situ XRD synchrotron experiments allowed to track the evolution of phases present during the TLAG-CSD growth. We confirm that compositions richer in Gd start at earlier times and imply faster growth processes than YBCO. The success of the in situ XRD synchrotron experiments in the analysis of combinatorial samples not only shows the richness of the method but also opens paths to the improvement of the setup and data acquisition schemes. Rapid on-the-flight measurements through compositionally graded samples should allow the accessibility and characterization of larger heating ramps and crystallization growth rates. ${ }^{71,72}$ All-in-all, the results obtained show that the combinatorial and high-throughput approach can be now moved forward to the fabrication of continuous compositional gradients. This will enable enhanced mapping of growth conditions, a fast screening of functional properties, the construction of libraries that include, for instance, other RE ions, liquid composition changes, nanoparticle percentages in nanocomposites, and the implementation of machine learning algorithms for a swift and smart optimization of TLAG-CSD REBCO film growth. Moreover, the methodology developed here may be extended to many different functional materials with different needs of fast screening and optimization. Ultimately, the combinatorial screening will also pave the way to novel material design strategies based on big data (i.e., data-driven approaches), aiming not only to accelerate the innovation throughput in the field of superconducting films and coated conductors but also in other fields of materials science.

\section{ASSOCIATED CONTENT}

\section{sI Supporting Information}

The Supporting Information is available free of charge at https://pubs.acs.org/doi/10.1021/acsami.0c18014.

Rheological measurements of REBCO inks (Figure S1); additional optical images of inkjet printing patterns (Figure S2); EDX elemental analysis (Figure S3); Nelson-Riley evaluation (Figure S4); raw 2D-XRD data (Figure S5); SEM images of samples (Figure S6); in situ XRD synchrotron diffractograms (Figure S7); raw 2D-XRD synchrotron image (Figure S8) (PDF)

\section{AUTHOR INFORMATION}

\section{Corresponding Authors}

Albert Queraltó - Institut de Ciència de Materials de Barcelona (ICMAB-CSIC), Campus UAB, 08193 Bellaterra, Catalonia, Spain; Email: aqueralto@icmab.es 
Teresa Puig - Institut de Ciència de Materials de Barcelona (ICMAB-CSIC), Campus UAB, 08193 Bellaterra,

Catalonia, Spain; Email: teresa.puig@icmab.es

\section{Authors}

Juri Banchewski - Institut de Ciència de Materials de Barcelona (ICMAB-CSIC), Campus UAB, 08193 Bellaterra, Catalonia, Spain

Adrià Pacheco - Institut de Ciència de Materials de Barcelona (ICMAB-CSIC), Campus UAB, 08193 Bellaterra, Catalonia, Spain

Kapil Gupta - Institut de Ciència de Materials de Barcelona (ICMAB-CSIC), Campus UAB, 08193 Bellaterra, Catalonia, Spain

Lavinia Saltarelli - Institut de Ciència de Materials de Barcelona (ICMAB-CSIC), Campus UAB, 08193 Bellaterra, Catalonia, Spain

Diana Garcia - Institut de Ciència de Materials de Barcelona (ICMAB-CSIC), Campus UAB, 08193 Bellaterra, Catalonia, Spain

Núria Alcalde - Institut de Ciència de Materials de Barcelona (ICMAB-CSIC), Campus UAB, 08193 Bellaterra, Catalonia, Spain

Cristian Mocuta - Synchrotron SOLEIL, L'Orme des Merisiers Saint-Aubin, 91192 Gif-sur-Yvette, France; (1) orcid.org/0000-0001-5540-449X

Susagna Ricart - Institut de Ciència de Materials de Barcelona (ICMAB-CSIC), Campus UAB, 08193 Bellaterra, Catalonia, Spain; 이잉.org/0000-0003-4196-2081

Flavio Pino - Institut de Ciència de Materials de Barcelona (ICMAB-CSIC), Campus UAB, 08193 Bellaterra, Catalonia, Spain

Xavier Obradors - Institut de Ciència de Materials de Barcelona (ICMAB-CSIC), Campus UAB, 08193 Bellaterra,

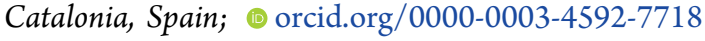

Complete contact information is available at: https://pubs.acs.org/10.1021/acsami.0c18014

\section{Author Contributions}

This manuscript was written through contributions of all authors. All authors have given approval to the final version of the manuscript.

\section{Notes}

The authors declare no competing financial interest.

\section{ACKNOWLEDGMENTS}

The authors acknowledge the European Research Council for the ULTRASUPERTAPE project (ERC-2014-ADG-669504) and EU COST action for CA16218 (NANOCOHYBRI). We also acknowledge financial support from the Spanish Ministry of Economy and Competitiveness, and Spanish Ministry of Science, Innovation and Universities through the "Severo Ochoa" Program for Centers of Excellence in R\&D (SEV2015-0496 and CEX2019-000917-S), SUMATE project (RTI2018-095853-B-C21, co-financed by the European Regional Development Fund). Synchrotron SOLEIL is acknowledged for granting the beamtime (under project no. 20190274) and P. Joly for setup assistance at the DiffAbs beamline. We also acknowledge support from the Catalan Government with 2017-SGR-1519 and the energy Catalan network E4S. A.Q. thanks the Spanish Ministry of Science, Innovation and Universities for his "Juan de la Cierva" postdoctoral fellowship (Grant no. IJC2018-035034-I). We acknowledge support of the publication fee by the CSIC Open Access Publication Support Initiative through its Unit of Information Resources for Research (URICI).

\section{REFERENCES}

(1) Shiohara, Y.; Taneda, T.; Yoshizumi, M. Overview of Materials and Power Applications of Coated Conductors Project. Jpn. J. Appl. Phys. 2012, 51, No. 010007.

(2) Obradors, X.; Puig, T. Coated Conductors for Power Applications: Materials Challenges. Supercond. Sci. Technol. 2014, 27, No. 044003.

(3) Ito, S.; Hashizume, H.; Yanagi, N.; Tamura, H. Advanced HighTemperature Superconducting Magnet for Fusion Reactors: Segment Fabrication and Joint Technique. Fusion Eng. Des. 2018, 136, 239246.

(4) Haran, K. S.; Kalsi, S.; Arndt, T.; Karmaker, H.; Badcock, R.; Buckley, B.; Haugan, T.; Izumi, M.; Loder, D.; Bray, J. W. High Power Density Superconducting Rotating Machines-Development Status and Technology Roadmap. Supercond. Sci. Technol. 2017, 30, No. 123002.

(5) Jha, A. K.; Matsumoto, K. Superconductive REBCO Thin Films and Their Nanocomposites: The Role of Rare-Earth Oxides in Promoting Sustainable Energy. Front. Phys. 2019, 7, 82.

(6) Cayado, P.; Erbe, M.; Kauffmann-Weiss, S.; Jung, A.; Hänisch, J.; Holzapfel, B. Chemical Solution Deposition of $\mathrm{Y}_{1-x} \mathrm{Gd}_{x} \mathrm{Ba}_{2} \mathrm{Cu}_{3} \mathrm{O}_{7-\delta^{-}}$ $\mathrm{BaHfO}_{3}$ Nanocomposite Films: Combined Influence of Nanoparticles and Rare-Earth Mixing on Growth Conditions and Transport Properties. RSC Adv. 2018, 8, No. 42398.

(7) Cayado, P.; Erbe, M.; Kauffmann-Weiss, S.; Bühler, C.; Jung, A.; Hänisch, J.; Holzapfel, B. Large Critical Current Densities and Pinning Forces in CSD-Grown $\mathrm{GdBa}_{2} \mathrm{Cu}_{3} \mathrm{O}_{7-\mathrm{x}}-\mathrm{BaHfO}_{3}$ Nanocomposite Films. Supercond. Sci. Technol. 2017, 30, No. 094007.

(8) Miura, S.; Yoshida, Y.; Ichino, Y.; Tsuruta, A.; Matsumoto, K.; Ichinose, A.; Awaji, S. Vortex Pinning at Low Temperature under High Magnetic Field in $\mathrm{SmBa}_{2} \mathrm{Cu}_{3} \mathrm{Oy}$ Superconducting Films with High Number Density and Small Size of $\mathrm{BaHfO}_{3}$ Nano-Rods. Supercond. Sci. Technol. 2015, 28, No. 114006.

(9) Majkic, G.; Pratap, R.; Xu, A.; Galstyan, E.; Higley, H. C.; Prestemon, S. O.; Wang, X.; Abraimov, D.; Jaroszynski, J.; Selvamanickam, V. Engineering Current Density over $5 \mathrm{kA} \mathrm{mm-2}$ at 4.2 K, $14 \mathrm{~T}$ in Thick Film REBCO Tapes. Supercond. Sci. Technol. 2018, 31, No. 10LT01.

(10) Dong, Z.; Ding, F.; Zhang, H.; Shang, H.; Huang, D.; Xu, W.; Li, T.; Zou, Q.; Gu, H. Preparation of High Performance YGdBCO Films by Low Fluorine TFA-MOD Process. J. Rare Earths 2020, 38, $755-762$.

(11) Matsushima, K.; Taka, C.; Nishida, A. Variations of Superconducting Transition Temperature in $\mathrm{YbBa}_{2} \mathrm{Cu}_{3} \mathrm{O}_{7-\delta}$ Ceramics by Gd substitution. J. Phys.: Conf. Ser. 2018, 969, No. 012059.

(12) Zhang, S.; Xu, S.; Fan, Z.; Jiang, P.; Han, Z.; Yang, G.; Chen, Y. Broad Temperature Study of RE-Substitution Effects on the In-Field Critical Current Behavior of REBCO Superconducting Tapes. Supercond. Sci. Technol. 2018, 31, No. 125006.

(13) Miura, M.; Kato, T.; Yoshizumi, M.; Yamada, Y.; Izumi, T.; Hirayama, T.; Shiohara, Y. Rare Earth Substitution Effects and Magnetic Field Dependence of Critical Current in $\mathrm{Y}_{1-x} \mathrm{RE}_{\mathrm{x}} \mathrm{Ba}_{2} \mathrm{Cu}_{3} \mathrm{O}_{\mathrm{y}}$ Coated Conductors with Nanoparticles $(\mathrm{RE}=\mathrm{Sm}, \mathrm{Gd})$. Appl. Phys. Express 2009, 2, No. 023002.

(14) Miura, M.; Kato, T.; Yoshizumi, M.; Yamada, Y.; Izumi, T.; Hirayama, T.; Shiohara, Y. Magnetic Field Dependence of Critical Current and Microstructure in TFA-MOD $\mathrm{Y}_{1-x}$ SmxBa2Cu3Oy with Nanoparticles for Coated Conductors. IEEE Trans. Appl. Supercond. 2009, 19, 3275-3278.

(15) Pavan Kumar Naik, S.; Muralidhar, M.; Jirsa, M.; Murakami, M. Enhanced Flux Pinning of Single Grain Bulk (Gd, Dy)BCO Superconductors Processed by Cold-Top-Seeded Infiltration Growth Method. Mater. Sci. Eng., B 2020, 253, No. 114494. 
(16) Pop, C.; Villarejo, B.; Pino, F.; Mundet, B.; Ricart, S.; de Palau, M.; Puig, T.; Obradors, X. Growth of All-Chemical High Critical Current $\mathrm{YBa}_{2} \mathrm{Cu}_{3} \mathrm{O}_{7-\delta}$ Thick Films and Coated Conductors. Supercond. Sci. Technol. 2019, 32, No. 015004.

(17) Lei, M.; Zhang, Y.; Zhao, Y. Performance of SCO Buffers Prepared by Dip Coating and Slot-Die Coating Methods. J. Supercond. Novel Magn. 2016, 29, 2587-2590.

(18) Solovyov, V.; Dimitrov, I. K.; Li, Q. Growth of Thick $\mathrm{YBa}_{2} \mathrm{Cu}_{3} \mathrm{O}_{7}$ Layers Via a Barium Fluoride Process. Supercond. Sci. Technol. 2013, 26, No. 013001.

(19) Yun, K. S.; Choi, B. D.; Matsumoto, Y.; Song, J. H.; Kanda, N.; Itoh, T.; Kawasaki, M.; Chikyow, T.; Ahmet, P.; Koinuma, H. VaporLiquid-Solid Tri-Phase Pulsed-Laser Epitaxy of $\mathrm{RBa}_{2} \mathrm{Cu}_{3} \mathrm{O}_{7-\mathrm{y}}$ SingleCrystal Films. Appl. Phys. Lett. 2002, 80, 61-63.

(20) Kursumovic, A.; Tomov, R. I.; Hühne, R.; MacManus-Driscoll, J. L.; Glowacki, B. A.; Evetts, J. E. Hybrid Liquid Phase Epitaxy Processes for $\mathrm{YBa}_{2} \mathrm{Cu}_{3} \mathrm{O}_{7}$ Film Growth. Supercond. Sci. Technol. 2004, 17, 1215-1223.

(21) Soler, L.; Jareño, J.; Banchewski, J.; Rasi, S.; Chamorro, N.; Guzman, R.; Yáñez, R.; Mocuta, C.; Ricart, S.; Farjas, J.; RouraGrabulosa, P.; Obradors, X.; Puig, T. Ultrafast Transient Liquid Assisted Growth of High Current Density Superconducting Films. Nat. Commun. 2020, 11, No. 344.

(22) Evans, J. R. G.; Edirisinghe, M. J.; Coveney, P. V.; Eames, J. Combinatorial Searches of Inorganic Materials Using the Ink-Jet Printer: Science, Philosophy and Technology. J. Eur. Ceram. Soc. 2001, 21, 2291-2299.

(23) Agrawal, A.; Choudhary, A. Perspective: Materials Informatics and Big Data: Realization of the "Fourth Paradigm" of Science in Materials Science. APL Mater. 2016, 4, No. 053208.

(24) Himanen, L.; Geurts, A.; Foster, A. S.; Rinke, P. Data-Driven Materials Science: Status, Challenges, and Perspectives. Adv. Sci. 2019, 6, No. 1900808.

(25) Green, M. L.; et al. Fulfilling the Promise of the Materials Genome Initiative with High-Throughput Experimental Methodologies. Appl. Phys. Rev. 2017, 4, No. 011105.

(26) Hattrick-Simpers, J. R.; Gregoire, J. M.; Kusne, A. G. Perspective: Composition-Structure-Property Mapping in HighThroughput Experiments: Turning Data into Knowledge. APL Mater. 2016, 4, No. 053211.

(27) Hattrick-Simpers, J. R.; et al. An Inter-Laboratory Study of ZnSn-Ti-O Thin Films Using High-Throughput Experimental Methods. ACS Comb. Sci. 2019, 21, 350-361.

(28) Vasudevan, R. K.; Choudhary, K.; Mehta, A.; Smith, R.; Kusne, G.; Tavazza, F.; Vlcek, L.; Ziatdinov, M.; Kalinin, S. V.; HattrickSimpers, J. Materials Science in the Artificial Intelligence Age: HighThroughput Library Generation, Machine Learning, and a Pathway from Correlations to the Underpinning Physics. MRS Commun. 2019, 9, 821-838

(29) Bag, M.; Jiang, Z.; Renna, L. A.; Jeong, S. P.; Rotello, V. M.; Venkataraman, D. Rapid Combinatorial Screening of Inkjet-Printed Alkyl-Ammonium Cations in Perovskite Solar Cells. Mater. Lett. 2016, 164, 472-475.

(30) Sánchez-Díaz, A.; Rodríguez-Martínez, X.; Córcoles-Guija, L.; Mora-Martín, G.; Campoy-Quiles, M. High-Throughput Multiparametric Screening of Solution Processed Bulk Heterojunction Solar Cells. Adv. Electron. Mater. 2018, 4, No. 1700477.

(31) Samoilenko, Y.; Yeung, G.; Zakutayev, A.; Reese, M. O.; Wolden, C. A. In Combinatorial Study of MZO Emitters for CdTe-Based Solar Cells, 2019 IEEE 46th Photovoltaic Specialists Conference (PVSC), 16-21 June 2019; pp 2498-2502.

(32) Brown, C. R.; McCalla, E.; Watson, C.; Dahn, J. R. Combinatorial Study of the Li-Ni-Mn-Co Oxide Pseudoquaternary System for Use in Li-Ion Battery Materials Research. ACS Comb. Sci. 2015, 17, 381-391.

(33) Carey, G. H.; Dahn, J. R. Combinatorial Synthesis of Mixed Transition Metal Oxides for Lithium-Ion Batteries. ACS Comb. Sci. 2011, 13, 186-189.
(34) Liu, P.; Guo, B.; An, T.; Fang, H.; Zhu, G.; Jiang, C.; Jiang, X. High Throughput Materials Research and Development for Lithium Ion Batteries. J. Materiomics 2017, 3, 202-208.

(35) Heinselman, K. N.; Lany, S.; Perkins, J. D.; Talley, K. R.; Zakutayev, A. Thin Film Synthesis of Semiconductors in the Mg$\mathrm{Sb}-\mathrm{N}$ Materials System. Chem. Mater. 2019, 31, 8717-8724.

(36) Talley, K. R.; Sherbondy, R.; Zakutayev, A.; Brennecka, G. L. Review of High-Throughput Approaches to Search for Piezoelectric Nitrides. J. Vac. Sci. Technol., A 2019, 37, No. 060803.

(37) Han, Y.; Bauers, S.; Zhang, Q.; Zakutayev, A. High-Throughput Fabrication and Semi-Automated Characterization of Oxide Thin Film Transistors. Chin. Phys. B 2020, 29, No. 018502.

(38) Jiang, C.; Wang, R.; Parkinson, B. A. Combinatorial Approach to Improve Photoelectrodes Based on $\mathrm{BiVO}_{4}$. ACS Comb. Sci. 2013 $15,639-645$

(39) Ndione, P. F.; Ratcliff, E. L.; Dey, S. R.; Warren, E. L.; Peng, H.; Holder, A. M.; Lany, S.; Gorman, B. P.; Al-Jassim, M. M.; Deutsch, T. G.; Zakutayev, A.; Ginley, D. S. High-Throughput Experimental Study of Wurtzite $\mathrm{Mn}_{1-x} \mathrm{Zn}_{\mathrm{x}} \mathrm{O}$ Alloys for Water Splitting Applications. ACS Omega 2019, 4, 7436-7447.

(40) Yuan, J.; Stanev, V.; Gao, C.; Takeuchi, I.; Jin, K. Recent Advances in High-Throughput Superconductivity Research. Supercond. Sci. Technol. 2019, 32, No. 123001.

(41) Zhigadlo, N. D.; Iranmanesh, M.; Assenmacher, W.; Mader, W.; Hulliger, J. Exploring Multi-Component Superconducting Compounds by a High-Pressure Method and Ceramic Combinatorial Chemistry. J. Supercond. Novel Magn. 2016, 30, 79-84.

(42) Barber, Z. H.; Blamire, M. G. High Throughput Thin Film Materials Science. Mater. Sci. Technol. 2013, 24, 757-770.

(43) McGinn, P. J. Thin-Film Processing Routes for Combinatorial Materials Investigations-A Review. ACS Comb. Sci. 2019, 21, 501515

(44) Shin, D. H.; Woo, S.; Yem, H.; Cha, M.; Cho, S.; Kang, M.; Jeong, S.; Kim, Y.; Kang, K.; Piao, Y. A Self-Reducible and AlcoholSoluble Copper-Based Metal-Organic Decomposition Ink for Printed Electronics. ACS Appl. Mater. Interfaces 2014, 6, 3312-3319.

(45) Calleja, A.; Ricart, S.; Palmer, X.; Luccas, R. F.; Puig, T.; Obradors, X. Water Determination of Precursor Solutions with Oxidant Cations by the Karl Fischer Method: The YBCO-TFA Case. J. Sol-Gel Sci. Technol. 2010, 53, 347-352.

(46) Basolo, S.; Bérar, J.-F.; Boudet, N.; Breugnon, P.; Caillot, B.; Clemens, J.-C.; Delpierre, P.; Dinkespiler, B.; Koudobine, I.; Meesen, C.; Menouni, M.; Mouget, C.; Pangaud, P.; Potheau, R.; Vigeolas, E. XPAD: Pixel Detector for Material Sciences. IEEE Trans. Nucl. Sci. 2005, 52, 1994-1998.

(47) Pangaud, P.; Basolo, S.; Boudet, N.; Bérar, J.-F.; Chantepie, B.; Clemens, J.-C.; Delpierre, P.; Dinkespiler, B.; Medjoubi, K.; Hustache, S.; Menouni, M.; Morel, C. XPAD3-S: A Fast Hybrid Pixel Readout Chip for X-Ray Synchrotron Facilities. Nucl. Instrum. Methods Phys. Res., Sect. A 2008, 591, 159-162.

(48) Jang, D.; Kim, D.; Moon, J. Influence of Fluid Physical Properties on Ink-Jet Printability. Langmuir 2009, 25, 2629-2635.

(49) Mattana, G.; Loi, A.; Woytasik, M.; Barbaro, M.; Noël, V.; Piro, B. Inkjet-Printing: A New Fabrication Technology for Organic Transistors. Adv. Mater. Technol. 2017, 2, No. 1700063.

(50) Liu, Y.; Derby, B. Experimental Study of the Parameters for Stable Drop-On-Demand Inkjet Performance. Phys. Fluids 2019, 31, No. 032004.

(51) Yunker, P. J.; Still, T.; Lohr, M. A.; Yodh, A. G. Suppression of the Coffee-Ring Effect by Shape-Dependent Capillary Interactions. Nature 2011, 476, 308-311.

(52) Villarejo, B. Synthesis of Defect Free $\mathrm{YBa}_{2} \mathrm{Cu}_{3} \mathrm{O}_{7-x}$ Films over $1 \mu \mathrm{m}$ by CSD Using Inkjet Printing; Universitat Autònoma de Barcelona: Bellaterra, 2018.

(53) Calvert, P. Inkjet Printing for Materials and Devices. Chem. Mater. 2001, 13, 3299-3305.

(54) Gómez-Núñez, A.; Alonso-Gil, S.; López, C.; Roura, P.; Vilà, A. Role of Ethanolamine on the Stability of a Sol-Gel ZnO Ink. J. Phys. Chem. C 2017, 121, 23839-23846. 
(55) Obradors, X.; Puig, T.; Ricart, S.; Coll, M.; Gazquez, J.; Palau, A.; Granados, X. Growth, Nanostructure and Vortex Pinning in Superconducting $\mathrm{YBa}_{2} \mathrm{Cu}_{3} \mathrm{O}_{7}$ Thin Films Based on Trifluoroacetate Solutions. Supercond. Sci. Technol. 2012, 25, No. 123001.

(56) Rasi, S.; Soler, L.; Jareño, J.; Banchewski, J.; Guzmán, R.; Mocuta, C.; Kreuzer, M.; Ricart, S.; Roura, P.; Farjas, J.; Obradors, X.; Puig, T. Relevance of the Formation of Intermediate Non-Equilibrium Phases in YBCO Film Growth by Transient Liquid Assisted Growth. J. Phys. Chem. C 2020, 124, 15574-15584.

(57) Grivel, J. C. Thermal Decomposition of $\mathrm{RE}\left(\mathrm{C}_{2} \mathrm{H}_{5} \mathrm{CO}_{2}\right)_{3} \cdot \mathrm{H}_{2} \mathrm{O}$

$(\mathrm{RE}=\mathrm{Dy}, \mathrm{Tb}, \mathrm{Gd}, \mathrm{Eu}$ and Sm. J. Therm. Anal. Calorim. 2014, 115, $1253-1264$

(58) Rasi, S.; Ricart, S.; Obradors, X.; Puig, T.; Roura, P.; Farjas, J. Thermal Decomposition of Yttrium Propionate: Film and Powder. J. Anal. Appl. Pyrolysis 2018, 133, 225-233.

(59) Van der Walt, S.; Colbert, S. C.; Varoquaux, G. The Numpy Array: A Structure for Efficient Numerical Computation. Comput. Sci. Eng. 2011, 13, 22-30.

(60) Reback, J.; et al. pandas-dev/pandas: Pandas 1.0. 5; Zenodo, 2020.

(61) Hunter, J. D. Matplotlib: A 2D Graphics Environment. Comput. Sci. Eng. 2007, 9, 90-95.

(62) Maier, W. F. Early Years of High-Throughput Experimentation and Combinatorial Approaches in Catalysis and Materials Science. ACS Comb. Sci. 2019, 21, 437-444.

(63) Hanak, J. J. The "Multiple-Sample Concept" in Materials Research: Synthesis, Compositional Analysis and Testing of Entire Multicomponent Systems. J. Mater. Sci. 1970, 5, 964-971.

(64) Mao, S. S.; Burrows, P. E. Combinatorial Screening of Thin Film Materials: An Overview. J. Materiomics 2015, 1, 85-91.

(65) Vegard, L. Die Konstitution Der Mischkristalle Und Die Raumfüllung Der Atome. Z. Phys. 1921, 5, 17-26.

(66) Nelson, J. B.; Riley, D. P. An Experimental Investigation of Extrapolation Methods in the Derivation of Accurate Unit-Cell Dimensions of Crystals. Proc. Phys. Soc. 1945, 57, 160-177.

(67) Llordés, A.; Palau, A.; Gázquez, J.; Coll, M.; Vlad, R.; Pomar, A.; Arbiol, J.; Guzmán, R.; Ye, S.; Rouco, V.; Sandiumenge, F.; Ricart, S.; Puig, T.; Varela, M.; Chateigner, D.; Vanacken, J.; Gutiérrez, J.; Moshchalkov, V.; Deutscher, G.; Magen, C.; Obradors, X. Nanoscale Strain-Induced Pair Suppression as a Vortex-Pinning Mechanism in High-Temperature Superconductors. Nat. Mat. 2012, 11, 329-336.

(68) Shiohara, Y.; Endo, A. Crystal Growth of Bulk High-Tc Superconducting Oxide Materials. Mater. Sci. Eng., R 1997, 19, 1-86.

(69) Gregoire, J. M.; Van Campen, D. G.; Miller, C. E.; Jones, R. J.; Suram, S. K.; Mehta, A. High-Throughput Synchrotron X-Ray Diffraction for Combinatorial Phase Mapping. J. Synchrotron Radiat. 2014, 21, 1262-1268.

(70) Lyu, Y.; Liu, Y.; Cheng, T.; Guo, B. High-Throughput Characterization Methods for Lithium Batteries. J. Materiomics 2017, 3, 221-229.

(71) Cook, P. K.; Mocuta, C.; Dufour, E.; Languille, M.-A.; Bertrand, L. Full-Section Otolith Microtexture Imaged by Local-Probe X-Ray Diffraction. J. Appl. Crystallogr. 2018, 51, 1182-1196.

(72) Gueriau, P.; Réguer, S.; Leclercq, N.; Cupello, C.; Brito, P. M.; Jauvion, C.; Morel, S.; Charbonnier, S.; Thiaudière, D.; Mocuta, C. Visualizing Mineralization Processes and Fossil Anatomy Using Synchronous Synchrotron X-Ray Fluorescence and X-Ray Diffraction Mapping. J. R. Soc. Interface 2020, 17, No. 20200216. 